\title{
As Compared to What? Characteristics of the AACSB Institutions That Utilize the Major Field Test in Business
}

\section{Authors: Agnieszka Bielinska-Kwapisz \& Bill W. Brown}

This is an Accepted Manuscript of an article published in Journal of Education for Business on September 29, 2014, available online:

http://www.tandfonline.com/10.1080/08832323.2014.916648.

Bielinska-Kwapisz, Agnieszka and F. William Brown. "As Compared to What? Characteristics of the AACSB Institutions That Utilize the Major Field Test in Business." Journal of Education for Business 89, no. 7 (2014): 373-381.

http://dx.doi.org/10.1080/08832323.2014.916648

Made available through Montana State University's $\underline{\text { ScholarWorks }}$ scholarworks. montana.edu 


\title{
Running head: AS COMPARED TO WHAT?
}

\section{As Compared to What?}

\section{Characteristics of the AACSB Institutions That Utilize the Major Field Test in Business}

\author{
Agnieszka Bielinska-Kwapisz \\ Bill W. Brown \\ Jake Jabs College of Business and Entrepreneurship \\ Montana State University \\ Bozeman, MT 59717 \\ (406) 994-4799 \\ akwapisz@montana.edu
}

Abstract

Publishers of the Major Field Test - Business (MFT-B), an assessment of learning instrument, provide a list of institutions utilizing the instrument and a table which allows comparison of local MFT-B mean scores to those of other institutions. The absence of information regarding the comparison group's characteristics limits the validity of that comparison. This study provides a comparison of the institutions accredited by the Association to Advance Collegiate Schools of Business and utilizing the MFT-B to those accredited institutions which do not, along with an estimation of the probability that a school will use the MFT-B for assessment purposes.

Keywords: Assessment, Major Field Test - Business 
The Major Field Test in Business (MFT-B) is a widely used Assessment of Learning (AOL) instrument intended for use in undergraduate business programs. The Educational Testing Service (ETS), MFT-B publisher, describes the instrument as going beyond an assessment of factual knowledge regarding business by evaluating senior students' ability to analyze and solve problems, understand relationships, and interpret material from their major field of study. The 120 multiple-choice questions in the MFT-B covers topics in nine subject areas: accounting, economics, management, quantitative business analysis, finance, marketing, legal and social environment, information systems, and international issues. This value proposition has attracted considerable attention among undergraduate business institutions in the United States. The ETS reports that from September 2010 to June 2012, 585 institutions in the United States utilized the MFT-B in their assessment of their business students' learning.

Given its wide usage, it is not surprising that the MFT-B has attracted considerable attention from researchers. To date, almost all of that attention has been directed towards efforts to identify student performance determinants. Standardized test scores (ACT/SAT), grade point averages (GPA), major field of study, and gender have been consistently cited as determinative covariates (e.g. Allen \& Bycio, 1997; Bagamery, Lasik, \& Nixon, 2005; Barboza \& Pesek, 2012; Bean \& Bernardi, 2002; Benham, Bielinska-Kwapisz, \& Brown, 2012, 2013; Bielinska-Kwapisz, Brown \& Semenik, 2012a, 2012b; Black \& Duhon, 2003; Bycio \& Allen; 2007; Contreras, Badua, Chen, \& Adrian, 2011; Gerlich \& Sollosy, 2009; Mason, Coleman, Steagall, Gallo, \& Fabritius, 2011; Mirchandani, Lynch, \& Hamilton, 2001; Rook \& Tanyel, 2009; Settlage \& Settlage, 2011; Terry, Mills, Rosa, \& Sollosy, 2009; and Zeis, Waronska, \& Fuller, 2009). All of these studies use a specific institution's data in order to gain insight into their students' performance. While these efforts can be helpful in understanding local performance, Bielinska- 
Kwapisz, Brown, \& Semenik (2012a) and others (e.g. Black \& Duhon, 2003; Bycio \& Allen; 2007; Contreras et al., 2009; Green, Stone, \& Zegeye, 2014) have pointed out that when interpreting an MFT-B institutional mean, the referent institution's characteristics need to be taken into account in order to make that interpretation meaningful.

Following administration of the MFT-B, ETS generates a local institutional Mean Total Score and nine Assessment Indicators associated with each of the previously described topical areas. While comparisons to scores from previously administered exams may be of interest, prior research has consistently shown that the primary way institutions interpret their performance is through a comparison of their institutional Mean Total Score to national averages (Bush, Duncan, Sexton, \& West, 2008; McLaughlin \& White, 2007; Wilson, 2008; Word \& Rook, 2012). ETS enables these comparisons by providing data tables that supply scaled scores and percentiles for institutional means drawn directly from all administrations of the MFT-B during a focal period (2013b). These tables allow for the comparison of school performance with all other domestic schools administering the MFT-B during the same period. An examination of the table permits a determination as to how many institutions in the data had mean scores lower than the local score.

Our study examines the limitations inherent in comparing local MFT-B scores to the Institutional Means Score Distribution, which ETS provides. Smith, Clements, and Olson (2010), describing advantages of the MFT-B test, stated: "The most frequently cited advantage is the ability to compare scores across national norms. . . If a school's percentile ratings are good, recruiters and public relations personnel may use those results in promotional materials to substantiate the quality of the college" (p. 251). However, Green et al. (2014) have a very different view and opined that the unknown nature of the comparison group constituted a major 
drawback of the MFT-B assessment: “A student's scaled score depends on his/her performance relative to that of all students who took the test. Who are these students?" (p. 22). They pointed out that "Even choosing to compare an institution's scores only against others accredited by or members of an accrediting agency is problematic as there are considerable quality differences across those institutions" (p. 7). This general problem is recognized by ETS, which notes that MFT-B score distributions should be comparative rather than normative, "because the institutions included in the data do not represent proportionally the various types of higher education institutions" (2013a, p. 5).

Unlike widely taken individual aptitude tests (e.g. SAT, ACT, GRE, GMAT), there is no reason to believe, in the case of the MFT-B, that the comparison scores necessarily come from typical or similarly situated undergraduate business programs. At present, we know little about the schools that use MFT-B assessment and there has not been any systematic examination to determine if the schools in the comparison group are representative of undergraduate business schools in general, or AACSB accredited schools specifically. As is more completely explained in the Data section below, in 2011-2012 there were 477 AACSB accredited undergraduate business programs in the United States. From September 2010 to June 2012, 585 institutions utilized the MFT-B but only 196 of these (34\%) were AACSB accredited. Institutions pointing to their MFT-B scores and percentile rankings as evidence that their program is fulfilling or making progress toward its stated mission, or that its students have a particular rank in business knowledge as compared to all other undergraduates, are in fact utilizing a referent group in which a minority (one third) have AACSB accreditation status. Thus, they run the risk of overor mis-stating the true nature of their rankings. 
Our study seeks to begin closing this gap in the literature by providing the first systematic, detailed description of schools that use MFT-B assessment. The MFT-B is often a cornerstone of institutional AOL programs and the results play an important role in curricular and accreditation decisions. A major part of our study's analysis is a data-based description of MFT-B utilization by AACSB accredited business schools and the characteristics of those schools. Our study also includes a probability estimate for whether or not a given school will use the MFT-B for assessment purposes. As of 2013, the base price for the online version of the exam was $\$ 25$ per test (\$24 for more than 100 tests) and the paper-based version price was $\$ 27$ each (\$26 for more than 100 tests) (ETS, 2013a). Our study's results should be of value since the test is relatively expensive, utilized for a significant purpose and appropriate interpretation of scores is important.

\section{Research Questions}

Given the lack of literature on the subject and the importance of the description of the comparison group for institutions that have already administered the MFT-B we form the following research questions. Answers to these questions will allow these institutions to better understand how to interpret the data generated by their institution's test result. They will also be helpful to institutions contemplating use of the MFT-B. Finally, they will shed light to the discussion on the validity of using the MFT-B test as an assessment tool as in the recent article published in this journal, Green et al. (2004), writes that comparisons of MFTB performances "across institutions are invalid because the test results are significantly driven by individual student characteristics of an unknown (and unknowable) group of students enrolled at diverse non-random business schools." (p.24). 
Research Question 1: Are AACSB accredited institutions using the MFT-B significantly different than the ones that do not use MFT-B?

Research Question 2: What are factors affecting probability that a school adopts the MFT-B for its assessment purposes?

\section{Method}

\section{Participants}

We matched information regarding all the available characteristics of U.S. AACSB accredited institutions (AACSB, 2013) with the ETS list of schools that use the MFT-B (2013b). The focus of our study is limited to data from institutions that offer undergraduate business degrees.

\section{Data}

Previous studies utilized surveys to estimate the percentage of AACSB institutions utilizing the MFT-B. Martell (2007) estimated that 46\% of AACSB accredited schools used the MFT-B as an assessment method, while Pringle and Michel (2006) estimated that $30 \%$ of AACSB accredited business schools used the MFT-B. The AACSB reports that in 2011-2012 there were 477 U.S. AACSB accredited schools offering undergraduate business degrees (65\% of which were accredited in business and $35 \%$ in both business and accounting) (AACSB, (2013). We summarize definitions and descriptive statistics regarding these institutions in Table 1. Of the 477 institutions which held an accreditation of their undergraduate business program during 2011-2012, 41\% $(n=196)$ administered the MFT-B during the most recent reporting period.

$<<$ Table 1 around here $>>$ 
Amongst the AACSB accredited institutions 70\% were public, 91\% offered master's general degrees, $65 \%$ offered master's specific degrees, and $27 \%$ offered doctoral degrees. The mean undergraduate in-state tuition was $\$ 15,306$, with a median of $\$ 8,933$. The mean out-ofstate tuition was $\$ 22,897$, with a median of $\$ 20,206$. The mean institutional operating budget was $\$ 17,379,398$ with a median of $\$ 9,780,006$ and ranged from $\$ 149,310$ to $\$ 188,680,970$. The mean budget per faculty member was $\$ 241,453$. The mean enrollment was 1,465 students, with 63 full time faculty members and 21 student-to-faculty ratio. On average, $84 \%$ of the full time faculty had a Ph.D. degree and 76\% were participating faculty.

We divided the states in which the AACSB accredited institutions were located into regions according to the United States Census Bureau classification. An examination of that distribution reveals that $40 \%$ of the schools were located in the South (S), $22 \%$ in the Midwest (MW), 21\% in the Northeast (NE), and 16\% in the West (W). The AACSB categorizes schools according to their general and scholarly orientation ${ }^{1}$. The general orientation consists of seven categories (BPA-1 to BPA-7) and lists schools with high, medium, and low emphasis in Teaching, Intellectual Contributions, and Service. Teaching was the high emphasis of almost half of the AACSB accredited schools (46\%), followed by institutions with an equal orientation toward Teaching and Intellectual Contributions emphasis (32\%). The scholarly orientation consists of 13 categories (BPB-1 to BPB-13) and lists schools as High, Medium, and Low emphasis in Discipline-based Scholarship, Contributions to Practice and Learning and Pedagogical Research. Discipline-based Scholarship was high emphasis for $24 \%$ of the AACSB accredited schools, followed by equal emphasis on Discipline-based Scholarship and Contributions to Practice (14\%), equal emphasis on Discipline-based Scholarship and

\footnotetext{
${ }^{1}$ See: https://datadirect.aacsb.edu/public/misc/clients/aacsb/help_orientation_codes.cfm?
} 
Contributions to Practice and Learning, and Pedagogical Research (13\%), and by Contributions to Practice $(12.9 \%)$.

The Carnegie Foundation for the Advancement of Teaching provides a classification scheme of colleges and universities ${ }^{2}$. The largest percentage of AACSB accredited institutions, 34\%, were classified as Master's Colleges and Universities (larger programs), followed by Research Universities (high research activity), 19\%, and Research Universities (very high research activity), 15\%. Aggregating to the broad categories, most of the focal schools were Master's Colleges and Universities (48\%) or Research Universities and Doctoral/Research Universities (43\%).

Table 2 shows correlations between all institutional variables. As expected, private schools charge significantly higher tuition. Not surprisingly, operating budget per faculty member was higher in schools that charge higher in-state and out-of-state tuition.

$$
<<\text { Table } 2 \text { around here }>>
$$

\section{Results}

\section{Simple Comparisons}

There are numerous significant differences between AACSB schools that use and do not use the MFT-B test for their assessment purposes. Institutions that do not utilize the MFT-B have significantly higher enrollment $(1,717$ vs. 1,105 ; t-stat=5.76), more faculty (76 vs. 45 ; tstat=4.60), a slightly higher percent of faculty with Ph.D. degrees (85 vs. 83\%; t-stat=1.65), higher all types of tuition (e.g. in-state undergraduate tuition $\$ 16,928$ vs. $\$ 13,027$; t-stat=3.48), budgets $(\$ 22,829,361$ vs. $\$ 9,690,531$; t-stat $=7.67)$, and budgets per faculty members $(\$ 277,141$ vs. $\$ 191,298$; t-stat=7.22). Most of the differences were highly significant suggesting that

\footnotetext{
${ }^{2}$ See: http://classifications.carnegiefoundation.org/descriptions/basic.php
} 
AACSB accredited institutions using the MFT-B significantly differ from the ones that do not. We observed no significant differences between the student-faculty ratio ( 21 vs. 20 ; $t$-stat $=0.91)$ and percentage of participating faculty (75 vs. $76 \%$; t-stat $=0.73$ ).

Our examination of the proportional measures confirmed and further illuminated these differences with significantly more public than private universities use the MFT-B (45\% vs. $33 \% ; \chi^{2}=5.2$ ) and significantly more schools which are accredited only in business vs. business and accounting use the MFT-B (50 vs. $\left.27 \% ; \chi^{2}=24.1\right)$. In addition, AACSB accredited undergraduate institutions utilizing the MFT-B are more likely to offer only a general master's degree $\left(81 \%\right.$ vs. $\left.38 \% ; \chi^{2}=27.9\right)$ and not any specific master's degrees $\left(33 \%\right.$ vs. $\left.58 \% ; \chi^{2}=25.3\right)$ or doctorates $\left(21 \%\right.$ vs. $\left.49 \% ; \chi^{2}=29.2\right)$ than those institutions that do not utilize the MFT-B.

We found some significant differences between the four geographical regions with the MFT-B used the most in the South (48\% of AACSB schools) and the least in the West (31\%). The 4-sample test for equality of proportions was rejected at 0.05 significance level $\left(\chi^{2}=7.92 ; p\right.$ value $=0.048)$.

Most importantly, we found significant differences between schools' general orientations with the highest proportion of AACSB schools that use the MFT-B having Teaching as High Emphasis: $58 \%$ of schools coded as BPA-1 and 56\% of schools coded as BPA-6 using the MFTB. Only $13 \%$ of AACSB accredited undergraduate business institutions, with Intellectual Emphasis as a High Emphasis used the MFT-B. There were no schools with a BPA-4 category and one with BPA-3. Therefore, we removed these categories from the sample due to not having enough observations. The null hypothesis of no differences between the five BPA categories was rejected at $1 \%$ significance level using the 5-sample test for equality of proportions $\left(\chi^{2}=60.89\right.$; $p$-value $=1.9 \mathrm{e}-12)$ 
Similarly, we found significant differences while comparing proportions of schools using the MFT-B with respect to their scholarly orientation with schools coded as BPB-9 (Equal Emphasis on Discipline-based Scholarship and Learning \& Pedagogical Research) using the MFT-B the most (75\%) and BPB-5 (Learning \& Pedagogical Research) and BPB-1 (Disciplinebased Scholarship) using the MFT-B the least (25\% and 29\%, respectively).

Using the broad Carnegie Class 2005 classification, 77\% of Baccalaureate Colleges, 51\% of Master's Colleges and Universities, and only 27\% of Research Universities used the MFT-B test. The class 4 defined as Other Schools had only four observations and we removed it from the analysis. We rejected the null hypothesis of no differences between the three Carnegie categories at a $1 \%$ significance level using the 3 -sample test for equality of proportions $\left(\chi^{2}=41.52\right.$; $p$-value $=9.65 \mathrm{e}-10)$.

In summary, answering our Research Question 1, AACSB accredited undergraduate business programs that utilize the MFT-B tend to have the following characteristics as compared to AACSB accredited undergraduate business programs that do not utilize the MFT-B:

- Lower enrollment

- Less faculty

- A slightly lower percentage of Ph.D. faculty

- Charge lower tuition

- Have lower operating budgets and lower budgets per faculty member

- Are predominantly public institutions

- Are less likely to have Ph.D. or M.S. specific programs

- Are more likely to be AACSB accredited in Business only (as opposed to Business \& Accounting) 
- Tend to have a general teaching orientation

- Tend to have Carnegie classification of Baccalaureate

\section{Estimation: Factors affecting probability that a school uses the MFT-B}

We ran a logistic regression to identify factors affecting the probability that an AACSB institution uses the MFT-B. We estimated the following model:

$\operatorname{Prob}($ MFT-B $=1)=\mathrm{F}($ Carnegie Classification, General Orientation, Public, Others, Region $) .(1)$

In the above equation, the Carnegie Classification is a set of dummy variables for Master and Baccalaureate Carnegie Classifications. Institutions in the data set with a Carnegie Classification of Research Universities were used as a reference category (as before, Carnegie Other Category was omitted due to too small sample size). The General Orientation is a set of dummy variables for schools general orientation. We chose General Orientation High Emphasis on Intellectual Contributions (BPA-2) as a reference category (as before, we omitted BPA-3 and BPA-4 due to too small sample size). In equation (1), Public is a dummy variable that takes a value of one when an institution is public and zero when private and Others variable is a percentage of other schools in a given state that utilize the MFT-B test (not including itself). Finally, Region is a set of dummy variables that control for schools' geographical location. For Region, West was chosen as a reference category.

Since Carnegie Classification and General Orientation correlate (Table 2) with many other characteristics (Enrollment, NrFaculty, PhDfaculty, Budget, Tuition), these variables were used to control for the type of the school. Because the dependent variable (use of MFT-B) was binary, we estimated the model using a logistic regression. We report results in Table 3 . Two models are presented where Model 1 includes and Model 2 excludes regional dummies. 
Study results indicate that schools with a Carnegie Classification of Baccalaureate are much more likely to adopt the MFT-B than Research Universities. Schools with High Emphasis on Teaching Contributions (BPA-1, BPA-5, and BPA-6) are much more likely to use the MFT-B as compared to schools with High Emphasis on Intellectual Contributions (BPA-2). Public schools were more likely to use the MFT-B than private institutions. Holding all other variables constant, the odds that a public university will use the MFT-B, over the odds that a private university would, is $1.95(\exp (0.67))$. In other words, in terms of percentage change, the odds that a public institution with an AACSB accredited undergraduate business program would utilize the MFT-B are 95\% higher than for an otherwise similarly situated private institution. We found no effect for regional differences or the percentage of other schools using the MFT-B in the focal state.

Due to the very substantial difference between the percentages of public and private schools using the MFT-B, and because many other variables are heavily correlated with this type of school, we ran separate regressions for public and private schools. As before, we used logistic regression for the model estimates. We report the results in Table 4.

$<<$ Table 4 around here. $>>$

For public schools, most of the results are similar to the regression for all schools reported in Table 4. As before, Baccalaureate Carnegie Class classification public schools and schools with High Emphasis on Teaching Contributions are much more likely to adopt the MFTB. However, for public schools, it is more likely that a school would use the MFT-B if there were high percentages of other schools in the state using the MFT-B. Schools located in the MW are more likely to use the MFT-B than schools in the West. Holding all other variables constant, for every $1 \%$ increase in the number of other schools that use the MFT-B in a given state, the 
odds of the focal school using the MFT-B increases by a factor of $1.7(\exp (0.01))$ : there is a $7 \%$ increase in the probability of using the MFT-B for every $1 \%$ increase in other universities in the state using the MFT-B.

The full regression for private schools was not significant. Therefore, (using backward elimination) we performed a limited regression. We report results in Table 4, indicating that Private Baccalaureate and Master's Carnegie Class classification schools are more likely to use MFT-B than Research Universities.

\section{Prediction}

From the above estimation, to find a probability, $p$, that a given AACSB institution would use the MFT-B, any school (public or private) can use the following model (from Table 3 results):

$\operatorname{Ln}(\mathrm{p} /(1-\mathrm{p}))=-3.28+0.67 *$ Public $+0.29 *$ CMaster $+1.79 * \mathrm{CBacc}+2.04 * \mathrm{BPA} 1+0.81 * \mathrm{BPA} 5+$ $1.66 * \mathrm{BPA} 6-0.09 * \mathrm{BPA} 7+0.01 *$ Others $+0.43 * \mathrm{NE}+0.53 * \mathrm{MW}+0.56 * \mathrm{~S}$.

For example, a probability that a public school with a Research Universities Carnegie Classification, BPA1 General Orientation, in a W state where all other AACSB accredited universities in the state use the MFT-B would be $56 \%$ - the result obtained by solving for $\mathrm{p}$ in the following equation:

$\operatorname{Ln}(p /(1-p))=-3.28+0.67 * 1+0.29 * 0+1.79 * 0+2.04 * 1+0.81 * 0+1.66 * 0-0.09 * 0+0.01 * 100+$ $0.43 * 0+0.53 * 0+0.56 * 0=0.264$

If this school had a Master's Carnegie Classification instead, the probability would rise to $63 \%$. If this school had Baccalaureate Carnegie Classification, the probability would be $89 \%$. If 
those using this model desire not to include geographical information, they should apply coefficients reported in Table 3, Model 2.

Estimation that is more precise can be derived from the specific model for private or public schools. Therefore, the following model can be used for public schools (Table 4, Model 1):

$\operatorname{Ln}(\mathrm{p} /(1-\mathrm{p}))=-3.23+0.33 *$ CMaster $+2.43 * \mathrm{CBacc}+2.24 * \mathrm{BPA} 1+0.95 * \mathrm{BPA} 5+2.60 * \mathrm{BPA} 6-$

$0.39 * \mathrm{BPA} 7+0.01 *$ Others $+0.54 * \mathrm{NE}+0.82 * \mathrm{MW}+0.65 * \mathrm{~S}$.

For the school described above, this probability would be $59.5 \%$, while the same school with a Master's Carnegie Classification would be 67\%, and Baccalaureate 94\%.

Alternatively, the model without geographical location can be used (Table 4, Model 2):

$\operatorname{Ln}(\mathrm{p} /(1-\mathrm{p}))=-2.02+0.30 * \mathrm{CM}$ aster $+2.29 * \mathrm{CBacc}+2.20 * \mathrm{BPA} 1+1.02 * \mathrm{BPA} 5+2.40 * \mathrm{BPA} 6+$ $0.33 *$ BPA7

Using this equation, the probability for the above school is $54.6 \%$, while the same school with Master's Carnegie Classification would be $62 \%$, and Baccalaureate $92 \%$.

For a private school, using the results reported in Table 4, the probability that a Research Carnegie University uses the MFT-B would be 22\%, Master's 38\%, and Baccalaureate $60 \%$.

\section{Discussion}

As a condition of gaining and sustaining external accreditation by the AACSB, business programs are required to provide a mission statement which specifies what the institution seeks to accomplish with their students and AOL assessments indicating the extent to which this is being accomplished. As previously noted, 41\% of AACSB accredited undergraduate programs utilize the MFT-B as a part of their satisfaction of their AOL. 
The ETS provides tables that can be used to compare a local institutional mean score to those of all other institutions also using the MFT-B. The meaningfulness and utility of this comparison may in fact be quite limited for two reasons 1) not all institutions with undergraduate business programs utilize the MFT-B and 2) there is no reason to believe that those schools that do utilize the MFT-B are representative of all undergraduate programs. Green, et al. (2014), cites this lack of direct and meaningful comparability as a disadvantage associated with the use of the MFT-B. Our study provides an empirical measurement of the extent four-year undergraduate business programs accredited by the AACSB utilize the MFT-B, and a description of the characteristics of those programs.

Our analysis of the characteristics of the AACSB accredited undergraduate institutions utilizing the MFT-B provides at least some illumination on the characteristics of the institutions that appear in the ETS comparative tables. First, we compared the characteristics of accredited programs that use and do not use the MFT-B. Our results show that schools that are public, classified as Baccalaureate Carnegie Class Classification, and that put High Emphasis on Teaching Contributions (BPA-1, BPA-5, and BPA-6) are much more likely to use the MFT-B than private universities and research universities with High Emphasis on Intellectual Contributions (BPA-2).

Second, we provide a model that institutions could use to assist in determining how comparable the schools in the ETS comparison set are to their own institution, perhaps assisting in the decision of whether or not to utilize the MFT-B. The higher the probability received from the model, the more meaningful the comparison with other schools will be. For example, for a public school with a Research Universities Carnegie Classification, BPA1 General Orientation, in a W state where all other AACSB accredited universities in the state use the MFT-B, the 
probability that a similar school (same Carnegie Classification and General Orientation) uses the MFT-B is $51 \%$. Programs and institutions may also find it useful to compare their characteristics to other schools either using or not using the MFT-B.

Additional studies examining the extent of utilization and the characteristics of nonAACSB accredited institutions utilizing the MFT-B could provide additional insights into comparability across programs. Presently the ETS provides the opportunity for institutions utilizing the MFT-B to order a Custom Comparative Data Report that they can use to compare a local score to a reference group of ten or more other selected institutions. Certainly, this provides institutions, if they have access to the necessary metrics, with at least a limited opportunity to create a more meaningful comparison than the use of the overall mean scores provided by ETS. ETS should be encouraged to provide the opportunity for MFT-B users to create more robust custom comparison sets through the inclusion of accreditation status and other publically available institutional characteristics such as those used in our study. To do so would make the MFT-B a more meaningful assessment of learning at the local level and eminently more attractive for use at the national level. 


\section{References}

Allen, J. S., \& Bycio, P. (1997). An evaluation of the Educational Testing Service Major Field Achievement Test in Business. Journal of Accounting Education, 15(4), 503-514.

Association to Advance Collegiate Schools of Business (AACSB) (2013). Retrieved from $\underline{\text { http://www.aacsb.edu/ }}$

Bagamery, B. D., Lasik J. J., \& Nixon D. R. (2005). Determinants of success on the ETS Business Major Field Exam for students in an undergraduate multisite regional university business program. Journal of Education for Business, 81(1), 55-63.

Barboza, G. A. \& Pesek, J. (2012). Linking course-embedded assessment measures and performance on the Educational Testing Service Major Field Test in Business. Journal of Education for Business, 87(2), 102-111.

Bean, D. F., \& Bernardi, R. A. (2002). Performance on the Major Field Test in Business: The explanatory power of SAT scores and gender. Journal of Private Enterprise, 17(2), 172178.

Benham, H. C., Bielinska-Kwapisz, A., \& Brown, F. W. (2012). Software applications course as an early indicator of academic performance. Research in Higher Education Journal, 19, 116.

Bielinska-Kwapisz, A., \& Brown, F. W. (2013). Differential gender performance on the Major Field Test-Business. Journal of Education for Business, 88(3), 159-166.

Bielinska-Kwapisz, A., \& Brown, F. W. (2012). The impact of intellectual heterogeneity on academic performance in business education. Research in Higher Education Journal, 16, 115. 
Bielinska-Kwapisz, A., Brown, F. W., \& Semenik, R. J. (2012a). Is higher better? Determinants and comparisons of performance on the Major Field Test—Business. Journal of Education for Business, 87(3), 159-169.

Bielinska-Kwapisz, A., Brown, F. W., \& Semenik, R. J. (2012b). Interpreting standardized assessment test scores and setting performance goals in the context of student characteristics: The Case of the Major Field Test in Business. Journal of Education for Business, 87(1), 7-13.

Black, H. T., \& Duhon, D. L. (2003). Evaluating and improving student achievement in business programs: The effective use of standardized assessment tests. Journal of Education for Business, 79, 90-98.

Bush, H. F., Duncan, F. H., Sexton, E. A., \& West, C. T. (2008). Using the Major Field TestBusiness as an assessment tool and impetus for program improvement: Fifteen years of experience at Virginia Military Institute. Journal of College Teaching and Learning, 5(2), $75-88$.

Bycio, P., \& Allen J. S. (2007). Factors associated with performance on the Educational Testing Service (ETS) Major Field Achievement Test in Business (MFT-B). Journal of Education for Business, 82(4), 196-201.

Contreras, S., Badua, F, Chen, J. S., \& Adrian, M. (2011). Documenting and explaining Major Field Test results among undergraduate students. Journal of Education for Business, 86(2), $64-70$.

Educational Testing Service (ETS) (2013a). About ETS Major Field Test. Retrieved from http://www.ets.org/mft/about. 
Educational Testing Service (ETS) (2013b). Comparative data reports. Overview of the Comparative Data Guide. Retrieved from http://www.ets.org/mft/scores/compare data.

Gerlich, R. N., \& Sollosy, M. (2009). Evaluating the assessment outcomes in the principles of marketing course. Academy of Educational Leadership Journal, 13(1), 127-135.

Green, J. J., Stone, C. C., \& Zegeye, A. (2014). The Major Field Test in Business: A solution to the problem of assurance of learning assessment? Journal of Education for Business, 89(1), 20-26.

Martell, K. (2007). Assessing student learning: Are business schools making the grade? Journal of Education for Business, 82(4), 189-195.

Mason, P. M., Coleman, B. J., Steagall, J. W., Gallo, A. A., \& Fabritius, M. M. (2011). The use of the ETS Major Field Test for assurance of business content learning: Assurance of waste? Journal of Education for Business, 86(2), 71-77.

McLaughlin, P., \& White, J. T. (2007). Major Field Achievement Test in Business-guidelines for improved outcome scores-Part I. College Teaching Methods and Styles Journal, 3(2), $11-20$.

Mirchandani, D., Lynch, R., \& Hamilton, D. (2001). Using the ETS Major Field Test in Business: Implications for assessment. Journal of Education for Business, 77(1), 51-55.

Pringle, C. \& Michel, M. (2006). Assessment practices in AACSB-accredited business schools. Journal of Education for Business, 82(4), 202-211.

Rook, S. P., \& Tanyel, F. I. (2009). Value-added assessment using the Major Field Test in Business. Academy of Educational Leadership Journal, 13(3), 87-94.

Settlage, D. M. \& Settlage, L. A. (2011). A statistical framework for assessment using the ETS Major Field Test in Business. Journal of Education for Business, 86(5), 274-278. 
Smith, L. J., Clements, C., \& Olson, J. E. (2010). Local versus standardized content assessment: Some management implications, or why bother? Journal of Education for Business, 85(5), $249-257$.

Terry, N., Mills, L., Rosa, D. \& Sollosy, M. (2009). Do online students make the grade on the Business Major Field ETS exam? Academy of Educational Leadership Journal, 13(4), 109118.

Wilson, P. H. (2008). A protocol for analyzing the Major Field Test results. Journal of Business and Behavioral Sciences, 19(2), 33-45.

Word, W. R., \& Rook, S. P. (2012). Analyzing Major Field Test in Business assessment results. Journal of Business Administration Online, 12(1), 1-11.

Zeis, C., Waronska, A., \& Fuller, R. (2009). Value-added program assessment using nationally standardized tests: Insights into internal validity issues. Journal of Academy of Business and Economics, 9(1), 114-128. 